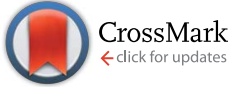

Cite this: Soft Matter, 2015, 11, 1352

\title{
The effects of globotriaosylceramide tail saturation level on bilayer phases $\uparrow$
}

\author{
Weria Pezeshkian, ${ }^{\text {ab }}$ Vitaly V. Chaban, ${ }^{a}$ Ludger Johannes, ${ }^{c}$ Julian Shillcock, ${ }^{d}$ \\ John H. Ipsen ${ }^{a}$ and Himanshu Khandelia*a
}

\begin{abstract}
Globotriaosylceramide $\left(\mathrm{Gb}_{3}\right)$ is a glycosphingolipid present in the plasma membrane that is the natural receptor of the bacterial Shiga toxin. The unsaturation level of $\mathrm{Gb}_{3}$ acyl chains has a drastic impact on lipid bilayer properties and phase behaviour, and on many $\mathrm{Gb}_{3}$-related cellular processes. For example: the Shiga toxin B subunit forms tubular invaginations in the presence of $\mathrm{Gb}_{3}$ with an unsaturated acyl chain $\left(U-G b_{3}\right)$, while in the presence of $\mathrm{Gb}_{3}$ with a saturated acyl chain $\left(\mathrm{S}-\mathrm{Gb}_{3}\right)$ such invagination does not occur. We have used all-atom molecular dynamics simulations to investigate the effects of the $\mathrm{Gb}_{3}$ concentration and its acyl chain saturation on the phase behaviour of a mixed bilayer of dioleoylphosphatidylcholine and $\mathrm{Gb}_{3}$. The simulation results show that: (1) the $\mathrm{Gb}_{3}$ acyl chains (longer tails) from one leaflet interdigitate into the opposing leaflet and lead to significant bilayer rigidification and immobilisation of the lipid tails. $\mathrm{S}-\mathrm{Gb}_{3}$ can form a highly ordered, relatively immobile phase which is resistant to bending while these changes for $\mathrm{U}-\mathrm{Gb}_{3}$ are not significant. (2) At low concentrations of $\mathrm{Gb}_{3}$, $\mathrm{U}-\mathrm{G} b_{3}$ and $\mathrm{S}-\mathrm{Gb}_{3}$ have a similar impact on the bilayer reminiscent of the effect of sphingomyelin lipids and (3) At higher $\mathrm{Gb}_{3}$ concentrations, $\mathrm{U}-\mathrm{Gb} 3$ mixes better with dioleoylphosphatidylcholine than $\mathrm{S}-\mathrm{Gb}_{3}$. Our simulations also provide the first molecular level structural model of $\mathrm{Gb}_{3}$ in membranes.
\end{abstract}

Received 5th November 2014

Accepted 16th December 2014

DOI: $10.1039 / \mathrm{c} 4 \mathrm{sm} 02456 \mathrm{~g}$

www.rsc.org/softmatter therapeutic immune response against cancer or intracellular pathogens. ${ }^{6-8}$

STxB binds up to $15 \mathrm{~Gb}_{3}$ lipids on the surface of the host cell membrane ${ }^{9}$ and allows the intracellular transport of the toxin via the retrograde route. ${ }^{2}$ STXB can also bind to, aggregate and form clusters on model membranes composed of dioleoylphosphatidylcholine (DOPC) and porcine $\mathrm{Gb}_{3}$, and if the membrane tension is sufficiently low, it drives the model membrane to invaginate and form tubular invaginations. ${ }^{2,10-12}$ The $\mathrm{Gb}_{3}$ lipid is a large and chemically diverse molecule. It contains three sugar moieties, $\alpha \mathrm{Gal}(1-4) \beta \mathrm{Gal}(1-4) \beta \mathrm{Glc}$, which are connected to a ceramide. The acyl chain structure of this ceramide varies in different $\mathrm{Gb}_{3}$ species and the saturation level of this acyl chain affects many $\mathrm{Gb}_{3}$ involving processes. For example binding of STxB to a bilayer composed of dioleoylphosphatidylcholine (DOPC) and $\mathrm{Gb}_{3}$ with saturated acyl chains does not lead to the formation of tubular invaginations, whereas invagination occurs for unsaturated $\mathrm{Gb}_{3} \cdot{ }^{\mathbf{2 , 1 1 , 1 3 , 1 4}}$ Also, a lipid bilayer containing DOPC, sphingomyelin, cholesterol and $\mathrm{Gb}_{3}$ phase separate into a liquid ordered $\left(\mathrm{l}_{\mathrm{o}}\right)$ and a liquid disordered $\left(l_{d}\right)$ phase at room temperature. Phase behaviour of such a bilayer is strongly influenced by STxB clustering as well as the saturation levels and length of the $\mathrm{Gb}_{3}$ fatty acyl chain. .1,13,15 $^{10}$ Recently, the condensation of phospholipid- $\mathrm{Gb}_{3}$ monolayers was studied, using X-ray reflectivity and grazing incidence X-ray diffraction. The capacity of $\mathrm{Gb}_{3}$ to condense the monolayers was

strongly affected by unsaturation levels of its acyl chain. ${ }^{16}$ ${ }^{a}$ Center for Biomembrane Physics (MEMPHYS), Department of Physics, Chemistry and
Pharmacy (FKF), University of Southern Denmark, Campusvej 55, 5230 Odense M,
Denmark. E-mail: hkhandel@sdu.dk
${ }^{b}$ TRANSPOL Molecular Neurobiochemistry, RUHR UNIVERSITAT BOCHUM, Bochum,
Germany
${ }^{c}$ U1143 INSERM-UMR3666 CNRS, Institut Curie, 26 Rue DUlm, 75248 Paris Cedex 05,
France
${ }^{d}$ Ecole Polytechnique Fèdèrale De Lausanne (EPFL), 1015 Lausanne, Switzerland
$\begin{aligned} & \dagger \text { Electronic supplementary information (ESI) available. See DOI: } \\ & \text { 10.1039/c4sm02456g }\end{aligned}$ 
Despite the important cellular roles of $\mathrm{Gb}_{3}$ and its significant impact on the physical behaviour of the lipid bilayers, it has not been studied by simulations before. Therefore, we use all-atom MD simulations to investigate a mixed bilayer of DOPC and $\mathrm{Gb}_{3}$ with two different acyl chain compositions, $\mathrm{Gb}_{3}-22: 0\left(\mathrm{~Gb}_{3}\right.$ with a saturated acyl chain with 22 carbon atoms) and $\mathrm{Gb}_{3}-22: 1$ $\left(\mathrm{Gb}_{3}\right.$ with an unsaturated acyl chain with 22 carbon atoms and a trans-double bound in $\left.\mathrm{C}_{13}-\mathrm{C}_{14}\right)$. We refer to the saturated and unsaturated versions of $\mathrm{Gb}_{3}$ as $\mathrm{S}-\mathrm{Gb}_{3}$ and $\mathrm{U}-\mathrm{Gb}_{3}$, respectively. The simulations reveal two important features of the $\mathrm{Gb}_{3}$ structure which strongly affect lipid bilayer physical properties. First: $\mathrm{Gb}_{3}$ fatty acyl chains from one leaflet interdigitate into the opposite monolayer leading to a reduction in chain fluctuations, ordering of all fatty acyl chains in the bilayer and result in a bilayer with higher bending resistance. Second: the degree of the $\mathrm{Gb}_{3}$ acyl chain saturation influences the phase behaviour of the bilayer where for fully saturated acyl chains an ordered phase was observed. Our simulations can explain several experimental observable processes, which we present in the Discussion section of the report.

\section{Methods, force field and systems}

\section{Methods}

We performed all-atom MD simulations of mixtures of DOPC and $\mathrm{Gb}_{3}$ lipids using GROMACS ${ }^{17-20}$ software and the CHARMM36 force field (FF). ${ }^{21,22}$ The $\mathrm{Gb}_{3}$ molecule had a $\mathrm{C}_{18}$ sphingosine tail and either a $22: 0$ acyl tail $\left(\mathrm{S}^{-G b_{3}}\right)$ or a $22: 1$ acyl tail unsaturated at $\mathrm{C}_{13}\left(\mathrm{U}-\mathrm{Gb}_{3}\right)$. For all systems, at least 100 water molecules (The TIP3P solvent model $^{23}$ ) per lipid were present (some simulations were repeated using the TIPS3P water model, ${ }^{24}$ and the differences in the results were within the range of error bars). $\mathrm{Na}$ and $\mathrm{Cl}$ ions corresponding to a biological concentration of $150 \mathrm{mmol}$ were present. Electrostatic interactions were treated with particle-mesh Ewald (PME) with a short range cutoff $1.2 \mathrm{~nm}$, and van der Waals interactions were switched off between 1.0 and $1.2 \mathrm{~nm}$. The system temperature was kept constant at $37{ }^{\circ} \mathrm{C}$ using Nose-Hoover temperature coupling..$^{25,26}$ Bonds containing hydrogen atoms were constrained using the LINCS algorithm. ${ }^{27}$ Parrinello-Rahman barostat pressure coupling ${ }^{28,29}$ was applied on all systems after equilibrating the systems with Berendsen pressure coupling. ${ }^{30}$ The leap frog integrator was used with a timestep of $2 \mathrm{fs}$.

\section{Force field parameters for $\mathbf{G b}_{3}$}

The $\mathrm{Gb}_{3}$ lipid contains three sugar moieties, $\alpha \mathrm{Gal}(1-4), \beta \mathrm{Gal}(1-4)$ and $\beta$ Glc (Blue segment of Fig. 1A), which are connected to ceramide. The sugar moiety was described by the CHARMM36 FF for carbohydrates. ${ }^{31-35}$ Point electrostatic charges needed for $\mathrm{HO}-\mathrm{CH}_{2}-\mathrm{CH}-\mathrm{CH}-\mathrm{CH}_{2}-\ldots$ (Green segment of Fig. 1A) are not provided in the CHARMM36 FF. As point electrostatic charges are unknown for the $\mathrm{HO}-\mathrm{CH}_{2}-\mathrm{CH}-\mathrm{CH}-\mathrm{CH}_{2}-\ldots$ moiety of $\mathrm{Gb}_{3}$, we have performed electronic structure calculations for a set of similar systems to obtain information on the electron density distribution. All-electron Möller-Plesset second-order perturbation theory, MP2, was used. The wave function was

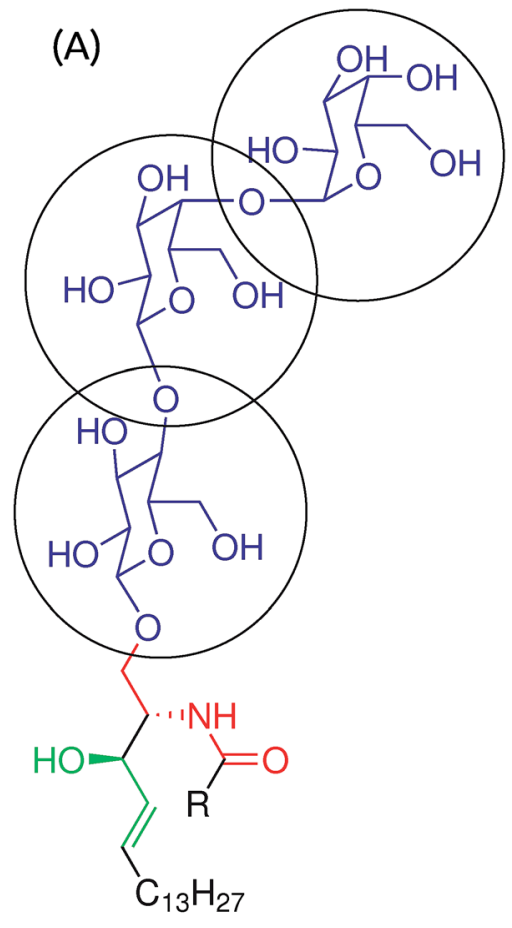

(B)<smiles>N[C@@H](CO)C(=O)N[C@@H](CO)C(=O)O</smiles>

Fig. 1 (A) Molecular structure of a $\mathrm{Gb}_{3}$ lipid. The acyl chain has 22 carbon atoms and it could be saturated $\left(\mathrm{S}-\mathrm{Gb}_{3}\right)$ or with a double bond between carbons 13 and 14 of the acyl chain $\left(U-G b_{3}\right)$. (B) A serineserine peptide bond.

constructed using the $6-311 \mathrm{G}$ basis set. Polarization and diffuse functions were added to this basis set. Additionally, polarization and diffuse functions were added to all hydrogen atoms. A strict self-consistent field convergence criterion of 10-9 Ha was applied. Geometries of the molecules were optimized at the same level of theory prior to the computation of the electrostatic potential (ESP). The ESP, derived from the electronic structure, was reproduced using a set of point charges centered on each atom, including hydrogen atoms. The atom spheres were defined according to the CHELPG scheme. ${ }^{36}$ The calculations were performed using the GAUSSIAN 09 program. ${ }^{37}$ We considered 4 model compounds, (1) $\mathrm{CH}_{2}=\mathrm{CH}-\mathrm{CH}_{2}-\mathrm{OH}$, (2) $\mathrm{CH}_{3}-\mathrm{CH}_{2}-\mathrm{CH}_{2}-\mathrm{OH}$, (3) $\mathrm{CH}_{3}-\mathrm{CH}=\mathrm{CH}-\mathrm{CH}_{3}$ and (4) $\mathrm{CH}_{3}-\mathrm{CH}=\mathrm{CH}-\mathrm{CH}_{2}-\mathrm{OH}$. The inclusion of enumerated compounds into consideration was necessary to ensure reasonable transferability of the assigned charges. Please refer to the ESI $\dagger$ for a more detailed description of the development of the force field. The derived charges are summarized in Table 1 . The $\mathrm{HO}-\mathrm{CH}_{2}-\mathrm{CH}-\mathrm{NH}-\mathrm{C}=\mathrm{O}$ moiety (Red segment of Fig. 1A and B) was described using serineserine peptide bond parameters in the CHARMM36 FF for proteins. Finally, the fatty acid chains were described by the CHARMM36 FF for lipids. 
Table 1 Extracted point charges using quantum calculation for structure $\mathrm{HO}-\mathrm{OH}-\alpha \mathrm{CH}^{1}-\beta \mathrm{CH}^{2}=\gamma \mathrm{CH}^{3}$

\begin{tabular}{lc}
\hline Atoms & Charge \\
\hline $\mathrm{OH}$ & -0.70 \\
$\mathrm{HO}$ & +0.40 \\
$\alpha \mathrm{C}$ & +0.55 \\
$\mathrm{H}^{1}$ & -0.05 \\
$\beta \mathrm{C}$ & -0.30 \\
$\mathrm{H}^{2}$ & +0.10 \\
$\gamma \mathrm{C}$ & -0.10 \\
$\mathrm{H}^{3}$ & +0.10
\end{tabular}

\section{Simulated systems}

Details of all simulated systems are present in Table 2. Five different $\mathrm{Gb}_{3}$ concentrations in a DOPC bilayer, 0, 12, 25, 50, and 100 percent, were simulated. Two extra simulations to investigate the phase separation tendency of $\mathrm{Gb}_{3}$ were performed (Table 2). For systems 1-9, initial configurations were built by placing all DOPC lipids on a lattice and then a sufficient amount of the DOPC lipids was randomly replaced by $\mathrm{Gb}_{3}$ lipids to the desired concentration. The number of $\mathrm{Gb}_{3}$ lipids in both the monolayers is equal. For $\mathrm{Gb}_{3}$ domain simulations (systems 10 and 11), 16 DOPC lipids were replaced by $16 \mathrm{~Gb}_{3}$ lipids in the middle of the upper mono-layer of the bilayer.

\section{Results}

The last $200 \mathrm{~ns}$ of the simulation outputs were used for data analysis. We performed an initial check on our simulation methodology by measuring the structural properties of a pure DOPC bilayer, and found that they are in good agreement with previous results from experiments and other simulations. In particular, the area per lipid and bilayer thickness were $64.7 \pm$ $1.2 \AA^{2}$ and $36.4 \pm 0.6 \AA$, which are close to the literature results of 68.0 $\AA^{2}$ and $36.6 \AA$ (ref. 38) extracted from simulations. Experimental values are $67.4 \AA^{2}$ (ref. 39) for the area per lipids and 36.1, 36.7 and 37.6 at 45,30 , and $15{ }^{\circ} \mathrm{C},{ }^{\mathbf{4 0 , 4 1}}$ respectively for the membrane thickness. The area and thickness are the two key mechanical properties that characterise a planar bilayer. The area per lipid responds sensitively to the lipid phase, and

Table 2 List of implemented simulations

\begin{tabular}{|c|c|c|c|c|}
\hline System & $\mathrm{DOPC} / \mathrm{Gb}_{3}$ & $\mathrm{Na} / \mathrm{Cl}$ & Solvent & Time (ns) \\
\hline $0 \% \mathrm{~Gb}_{3}$ & $128 / 0$ & $24 / 24$ & 9088 & 380 \\
\hline $12 \% \mathrm{U}-\mathrm{Gb}_{3}$ & $176 / 24$ & $37 / 37$ & 13689 & 320 \\
\hline $12 \% \mathrm{~S}-\mathrm{Gb}_{3}$ & $176 / 24$ & $36 / 36$ & 13625 & 330 \\
\hline $25 \% \mathrm{U}^{-G b_{3}}$ & $96 / 32$ & $25 / 25$ & 9359 & 325 \\
\hline $25 \% \mathrm{~S}-\mathrm{Gb}_{3}$ & $96 / 32$ & $23 / 23$ & 8784 & 250 \\
\hline $50 \% \mathrm{U}-\mathrm{Gb}_{3}$ & $64 / 64$ & $19 / 19$ & 7350 & 380 \\
\hline $50 \% \mathrm{~S}-\mathrm{Gb}_{3}$ & $64 / 64$ & $17 / 17$ & 6354 & 520 \\
\hline $100 \%$ U-Gb 3 & $0 / 128$ & $45 / 45$ & 17671 & 200 \\
\hline $100 \% \mathrm{~S}-\mathrm{Gb}_{3}$ & $0 / 128$ & $36 / 36$ & 13611 & 200 \\
\hline U-Gb $b_{3}$ domain & $322 / 16$ & $74 / 74$ & 28612 & 400 \\
\hline $\mathrm{S}-\mathrm{Gb}_{3}$ domain & $322 / 16$ & $62 / 62$ & 23735 & 400 \\
\hline
\end{tabular}

the thickness influences the membrane curvature modulus that governs its thermal fluctuations. Our results show that these mechanical properties strongly depend on the membrane composition and the structural details of the $\mathrm{Gb}_{3}$ acyl chains.

The rest of the paper is organized as follows. First, we report on the area and thickness using several different techniques for accurate measurement of the area per molecule. We then explore the influence of the $\mathrm{Gb}_{3}$ on the membrane dynamical properties, and measure the lipid tail order parameters, fatty acid tilt distributions, lipid diffusion, rotational correlation times and the tendency of $\mathrm{Gb}_{3}$ to phase separate. All of these properties are found to be sensitive to the $\mathrm{Gb}_{3}$ concentrations and the degree of $\mathrm{Gb}_{3}$ acyl chain saturation. In the Discussion section, we elaborate upon the main findings, and show how the simulations explain several previously unexplained experimental observations with regard to membrane invagination induced by Shiga toxins and the phase behaviour induced by $\mathrm{Gb}_{3}$.

\section{Area per lipid and membrane thickness}

We used three different methods to calculate the area per lipid.

Projected area per lipid $\left(a_{\mathrm{p}}\right)$, calculated from box size. For a one-component flat bilayer, the area per lipid is equal to $a_{\mathrm{p}}=$ $2 L_{x} L_{y} / N$ where $L_{x}$ and $L_{y}$ are the simulation box dimensions in the plane of the bilayer and $N$ is the number of the lipids in the system. Fig. 3 shows $a_{\mathrm{p}}$ as a function of time for different systems. The time average of $a_{\mathrm{p}}$ is presented in Table 3, column 2.

Projected area per lipid, calculated by Voronoi tessellation $\left(\boldsymbol{a}_{\mathbf{v}}\right)$. To obtain the individual area per lipid values in a mixed bilayer, we used Voronoi tessellation. The APL@Voro software was used. ${ }^{42}$ The data for this method are presented in Table 3, column 3.

Polynomial fitting. For a curved bilayer, neither of the previous methods can give an accurate value of the area per lipid. Instead, a polynomial fit to the membrane surface gives a better estimate of the area. Additionally, this method can be used to calculate the curvature and membrane thickness profile. A functional form for the bilayer surface can be obtained by fitting a polynomial of degree $s$ to the coordinates of specific

Table 3 Area per lipid and bilayer thickness: (1) $a_{\mathrm{p}}$ is the projected area per lipid calculated from box dimensions, (2) a real area estimated from polynomial fitting, (3) $a_{v}$ projected area calculated using Voroni tessellation and (4) bilayer thickness $\left(L_{m}\right)$

\begin{tabular}{|c|c|c|c|c|}
\hline System & $a_{\mathrm{p}}\left(\AA^{2}\right)$ & $a\left(\AA^{2}\right)$ & $a_{\mathrm{v}}\left(\mathrm{DOPC} / \mathrm{Gb}_{3}\right)$ & $L_{\mathrm{m}}(\AA)$ \\
\hline $0 \mathrm{~Gb}_{3}$ & $64.7 \pm 1.2$ & $65.3 \pm 0.9$ & $64.7 /-$ & $36.4 \pm 0.6$ \\
\hline $12 \mathrm{~S}-\mathrm{Gb}_{3}$ & $61.6 \pm 0.8$ & $61.9 \pm 0.7$ & $62.9 / 54.8$ & $38.9 \pm 0.5$ \\
\hline $12 \mathrm{U}^{-\mathrm{Gb}_{3}}$ & $62.2 \pm 0.8$ & $62.9 \pm 0.8$ & $63.0 / 53.8$ & $38.6 \pm 0.5$ \\
\hline $25 \mathrm{~S}^{-\mathrm{Gb}_{3}}$ & $59.2 \pm 1.0$ & $60.4 \pm 0.7$ & $61.1 / 53.7$ & $38.2 \pm 0.6$ \\
\hline $25 \mathrm{U}^{-\mathrm{Gb}_{3}}$ & $60.0 \pm 1.0$ & $61.7 \pm 1.1$ & $62.0 / 55.7$ & $37.4 \pm 0.5$ \\
\hline $50{\mathrm{~S}-G b_{3}}$ & $47.2 \pm 0.4$ & $50.8 \pm 1.2$ & $49.3 / 45.6$ & $43.1 \pm 0.3$ \\
\hline $50 \mathrm{U}-\mathrm{Gb}_{3}$ & $54.1 \pm 1.0$ & $55.0 \pm 1.0$ & $55.7 / 50.5$ & $39.0 \pm 0.5$ \\
\hline $100 \mathrm{U}-\mathrm{Gb}_{3}$ & $53.2 \pm 0.5$ & $58.0 \pm 1.0$ & - & - \\
\hline $100 \mathrm{~S}-\mathrm{Gb}_{3}$ & $52.6 \pm 0.5$ & $60.0 \pm 1.0$ & - & - \\
\hline
\end{tabular}


atoms, such as the phosphorus atom in DOPC lipids in one monolayer (eqn (1)).

$$
z(x, y)=\sum_{n, m=0}^{m+n \leq s} a_{(m, n)} x^{m} y^{n}
$$

where $m$ and $n$ are integer numbers and taking all values in the interval zero to $m+n \leq s . a_{(m, n)}$ are polynomial coefficients that are extracted from fitting. The area is evaluated as:

$$
A=\int_{0}^{L_{x}} \int_{0}^{L_{y}}\left(1+\left\langle z(x, y)_{x}\right\rangle_{\tau}^{2}+\left\langle z(x, y)_{y}\right\rangle_{\tau}^{2}\right)^{\frac{1}{2}} \mathrm{~d} x \mathrm{~d} y
$$

where $\langle A(x, y)\rangle_{\tau}$ is a time average of the function $A(x, y)$ in a specific time period, $\tau$, (we have used $\tau=20 \mathrm{~ns}$ ) that minimizes the effects of membrane protrusions and shape fluctuations due to thermal fluctuations. $z(x, y)_{x}$ and $z(x, y)_{y}$ are partial derivatives of the function $z(x, y)$ with respect to $x$ and $y$, respectively. For most of the systems (except for pure U-Gb 3 or S$\mathrm{Gb}_{3}$ ) the polynomial method gives similar values for area per lipid as the previous methods (Table 3). However, for the pure systems, the polynomial method extracts a higher value for the area per lipid, indicating that the pure $\mathrm{Gb}_{3}$ bilayers are not planar (Fig. 2C and D). In general, the increase in $\mathrm{Gb}_{3}$ concentration results in decreases in area per lipid and tighter bilayer packing (a similar result was observed experimentally ${ }^{16}$ ). The decrease in the area per lipid comes from two sources: increase in the amount of $\mathrm{Gb}_{3}$ which has a smaller area per lipid or a change in the membrane phase behaviour, from a disordered to an ordered phase. At low $\mathrm{Gb}_{3}$ concentration, the first effect plays a major role, because the area per lipid $\left(a_{v}\right)$ for $\mathrm{Gb}_{3}$ remains constant while the $a_{\mathrm{v}}$ for DOPC changed because the number of the DOPC lipids in contact with $\mathrm{Gb}_{3}$ increased. However, at high $\mathrm{S}-\mathrm{Gb}_{3}$ concentrations, the $\mathrm{Gb}_{3} a_{\mathrm{v}}$ is lowered significantly which indicates a change in the phase state of the bilayer. We will elaborate on this in the subsequent sections.

Bilayer thickness. We calculated membrane thickness as the distance between phosphorus atoms in the two monolayers $\left(L_{\mathrm{m}}\right)$ (Table 3, column 5). $L_{\mathrm{m}}$ does not change much for low $\mathrm{Gb}_{3}$ concentrations, but for high $\mathrm{S}-\mathrm{Gb}_{3}$ concentrations, this value increases significantly (a similar conclusion was made using $\mathrm{X}$ ray diffraction ${ }^{16}$ ). We did not report any value for $100 \% \mathrm{~Gb}_{3}$ since it is not a planar bilayer.

\section{Chain order parameter}

The orientational order of lipid chains is described by a deuterium order parameter which is given as:

$$
S_{\mathrm{CD}}=\frac{1}{2}\left\langle 3 \cos ^{2} \theta-1\right\rangle
$$

where $\theta$ is the angle between the $\mathbf{C}-\mathbf{H}$ vector and the bilayer normal. ${ }^{43,44}$ The reported order parameters in Fig. 4 show that $\mathrm{Gb}_{3}$ fatty acid chains are always more ordered compared to DOPC. Also, the $\mathrm{Gb}_{3}$ sphingosine chain is more ordered than the $\mathrm{Gb}_{3}$ acyl chain, which was also observed for sphingomyelin lipids in previous simulations. ${ }^{45}$ DOPC chains became more ordered with increasing $\mathrm{Gb}_{3}$ concentrations, because of unfavourable contacts of DOPC lipids with the $\mathrm{Gb}_{3}$ lipids, which results in the decrease of the molecular volume of both DOPC and $\mathrm{Gb}_{3}$. This effect is much stronger for $\mathrm{S}-\mathrm{Gb}_{3}$ because lipids with unsaturated acyl chains dissolve more easily into each other.
(A)

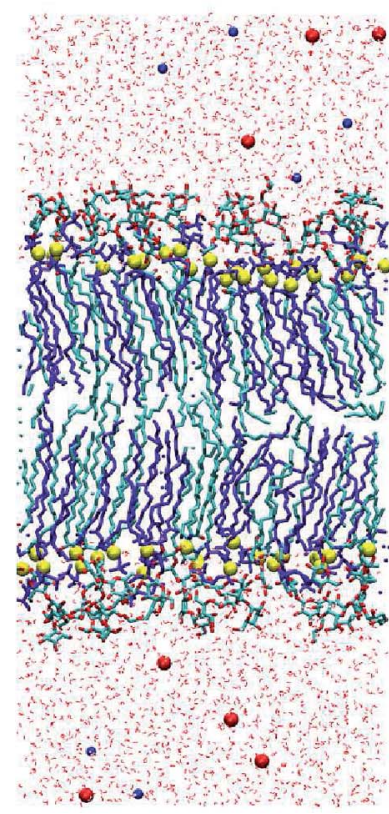

(B)

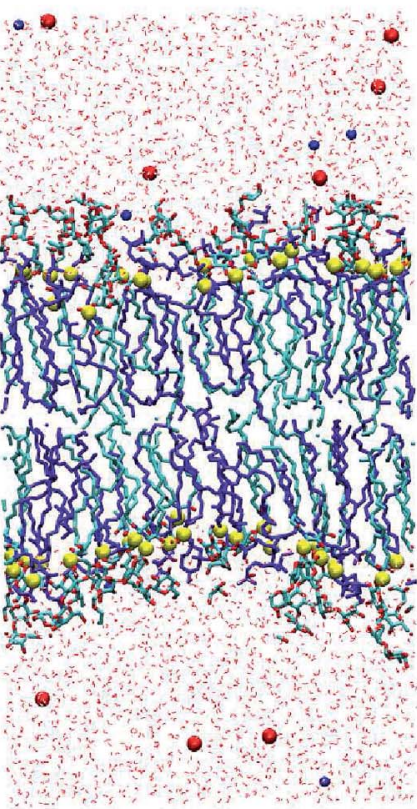

(C)

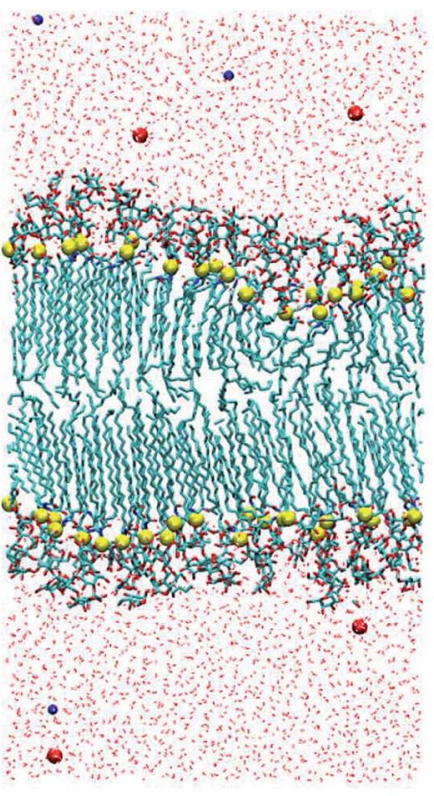

(D)

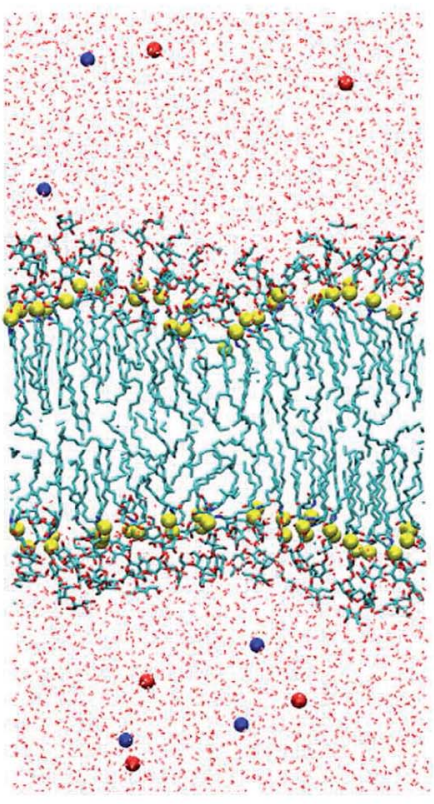

Fig. 2 Last snapshot of the system for (A) $50 \%{\mathrm{~S}-G b_{3}}$ (B) $50 \% \mathrm{U}-\mathrm{Gb}_{3}$ (C) $100 \% \mathrm{~S}-\mathrm{Gb}_{3}$ and (D) $100 \%$ U-Gb 3 . Yellow spheres are the first carbon atoms of the lipids hydrophobic moiety. $\mathrm{Gb}_{3}$ long chains (cyan color) interdigitate into the opposite monolayer. Also, the $\mathrm{S}-\mathrm{Gb} 3 \mathrm{kails}$ are highly ordered and tilted. These bilayers are not planar. 

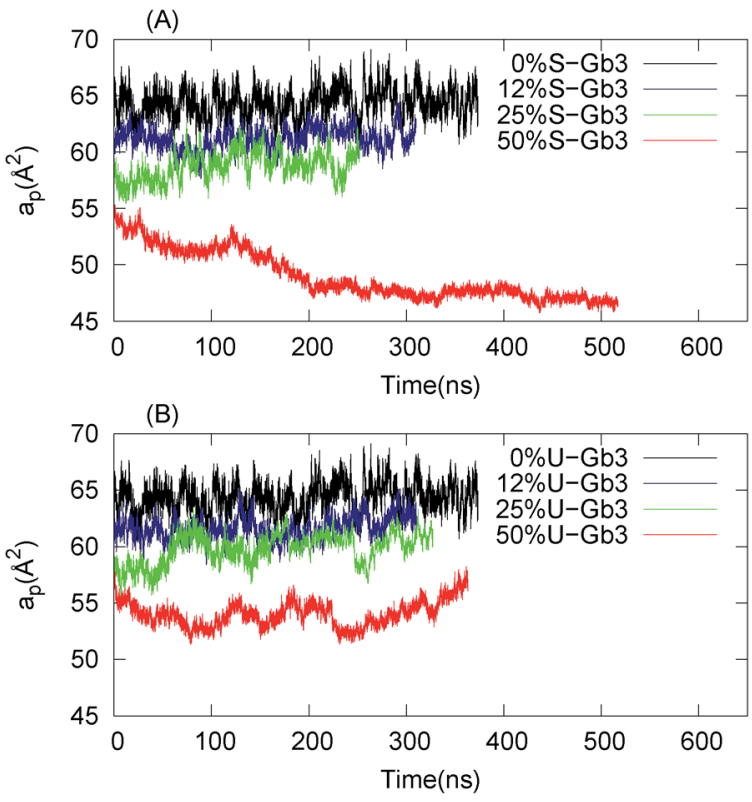

Fig. 3 Projected area per lipid $\left(a_{p}=2 L_{x} L_{y} / N\right)$ (A) mixture contains different concentrations of $\mathrm{S}-\mathrm{Gb}_{3}$ in a DOPC lipid bilayer. (B) Mixture contains different concentrations of $\mathrm{U}-\mathrm{Gb}_{3}$ in a DOPC lipid bilayer. Data for $100 \% \mathrm{~Gb}_{3}$ systems, were not shown, because $a_{\mathrm{p}}$ does not represent the correct area per lipid for these systems (see polynomial fitting subsection).

The very high order parameter for $50 \% \mathrm{~S}-\mathrm{Gb}_{3}$ indicates that this system is in an ordered phase state. The transition of this system from an initially disordered state to an ordered state can be observed from the distinct differences in the Voronoi diagrams at the beginning (Fig. 9A in the ESI $\dagger$ ) and the end of the simulation (Fig. 9B in the ESI $\dagger$ ). In the ordered state, many lipids acquire a very low area per lipid, depicted by dark blue colors. It is important to note that $\mathrm{S}_{-} \mathrm{Gb}_{3}$ orders the nearby DOPC acyl chains, whereas increasing the concentration of U$\mathrm{Gb}_{3}$ only has a small effect on the DOPC lipids, even up to $50 \%$ $\mathrm{U}_{-} \mathrm{Gb}_{3}$. The behaviour of the order parameter for the sphingosine chain of $\mathrm{Gb}_{3}$ in the low concentration regime is in good agreement with previous simulations of sphingomyelin lipids. ${ }^{45}$

\section{Lipid tilt}

Tilt of the hydrophobic chains of lipid with respect to the bilayer normal is a characteristic parameter of the internal structure of the membrane in ordered phases. In the $l_{d}$ phase, the average tilt is zero in the absence of constraints which is imposed by external objects (for example proteins). Changes in the lipid tilt are associated with energy cost and coupled to the membrane bending energy. ${ }^{46}$

The average orientation of the lipid chains is determined by the lipid tail director vector, $\mathbf{n}$ (Fig. 5A). Deviation of $\mathbf{n}$ from the bilayer normal (N) is quantified by the tilt vector $(\mathbf{m})$ which is given as:

$$
\mathbf{m}=\frac{\mathbf{n}}{\mathbf{n} \cdot \mathbf{N}}-\mathbf{N}
$$
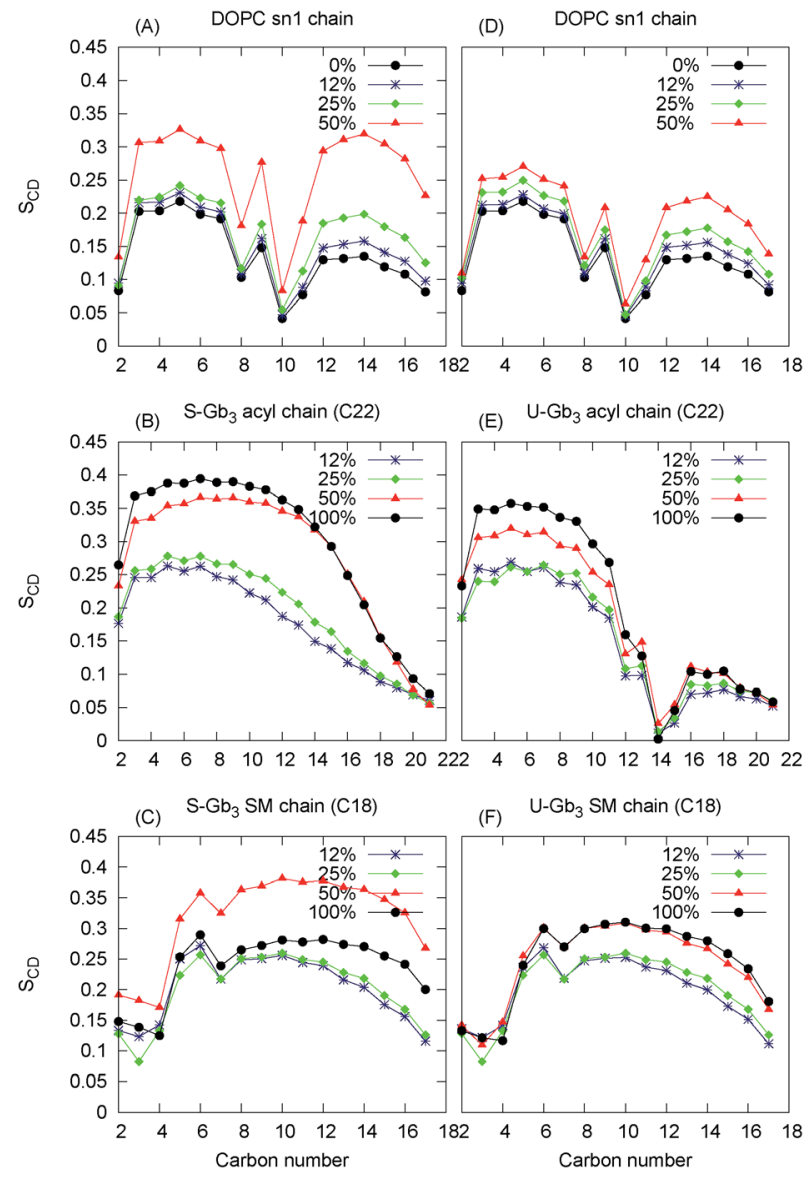

Fig. 4 Deuterium order parameter for $\mathrm{Gb}_{3}$ chains and DOPC sn1 chains: left panels are for the mixture of DOPC with $S-G b_{3}(A-C)$ and right pan are for the mixture of DOPC with $U-G b_{3}(D-F)$.

here we define the lipid director as a unit vector pointing from the lipid interface point to its corresponding tail point where the interface point is the carbon atom which connects both tails and the tail point is the midpoint between the last carbon atoms of the two chains of each lipid.

The probability of finding a lipid with a tilt angle between $\theta_{1}$ and $\theta_{2}$ (in the $l_{d}$ phase, the tilt is independent of $\phi$ because of the rotational symmetry) is given by:

$$
P\left(\theta_{1}, \theta_{2}\right)=\int_{\theta_{1}}^{\theta_{2}} p(\theta, \phi) \sin \theta \mathrm{d} \theta \mathrm{d} \phi
$$

where $\theta$ is the angle between $\mathbf{n}$ and $\mathbf{N}, \phi$ is the azimuthal angle and $p(\theta, \phi)$ is the density of the tilt probability. In the liquid phase, the membrane energy term corresponding to the lipid tilt is (for more details see ref. 46).

$$
F_{\text {tilt }}=\frac{1}{2} \int \mathrm{d} A \kappa_{\theta} \mathbf{m}^{2}=\frac{1}{2} \int \mathrm{d} A \kappa_{\theta} \tan ^{2}(\theta)
$$

where $\kappa_{\theta}$ is the tilt modulus. $p(\theta)$ is expected to have a form like:

$$
p(\theta) \propto \exp \left(-\frac{1}{2} a_{\mathrm{p}} \kappa_{\theta} \frac{\tan ^{2}(\theta)}{k_{\mathrm{B}} T}\right)
$$



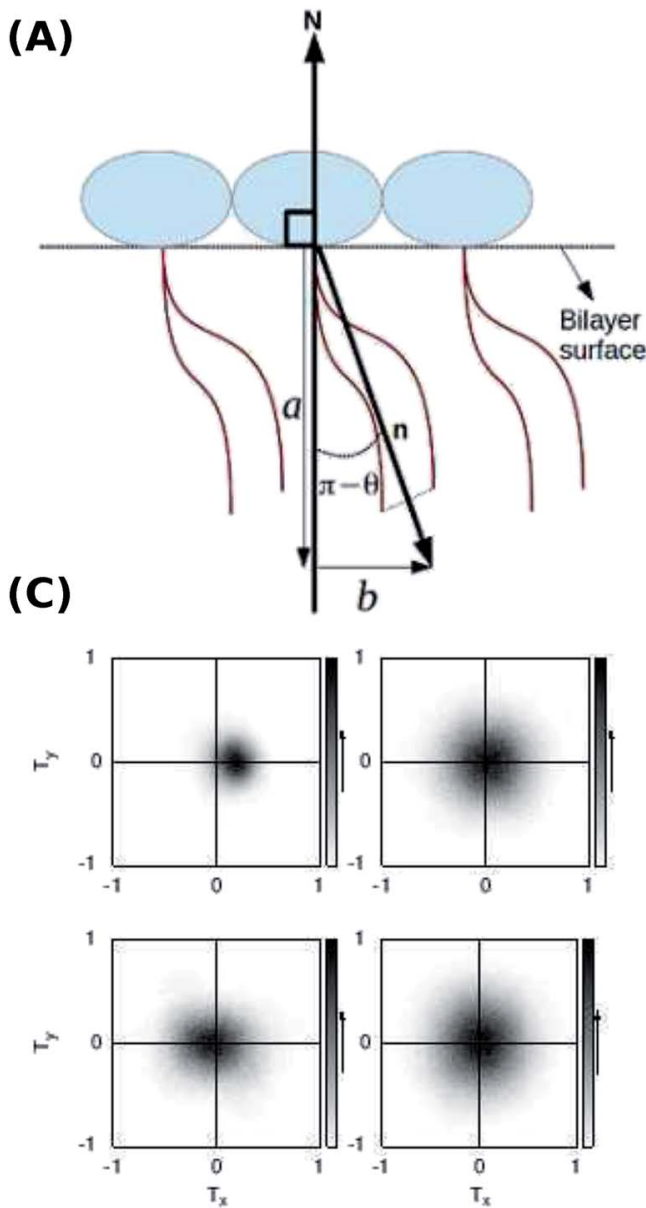

(B)
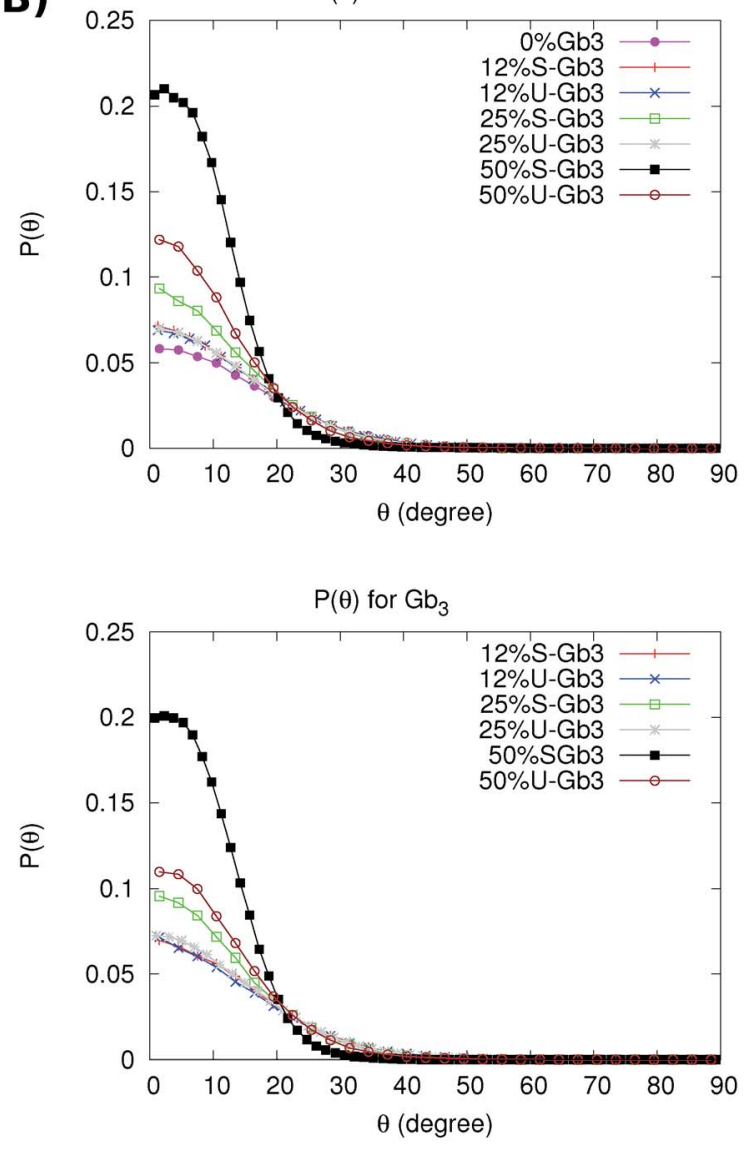

Fig. 5 (A) Director ( $\mathrm{n}$ ) is a unit vector along chains of a lipid and its deviation form $\mathrm{N}$ is given by tilt vector ( $\mathrm{m}$ ). The size of the tilt vector is equal to $\frac{|b|}{|a|}$ and is in the same direction as $b$. (B) Probability of lipid tilt. (Top) $p(\theta)$ for DOPC. (Bottom) $p(\theta)$ for $\mathrm{Gb}_{3}$. The cyan curve for $50 \% \mathrm{~S}^{-G b_{3}}$ does not peak at 0 , indicating a net lipid tilt. The corresponding curve for DOPC (cyan curve, top panel) also has a non-zero maximum. (C) $2 \mathrm{D}$ tilt distribution map. (Left top) 50\% S-Gb3. (Right top) 25\% S-Gb3. (Left bottom) 50\% U-Gb3. (Right bottom) pure DOPC.

where $a_{\mathrm{p}}$ is the projected area per lipid. Eqn (7) shows that for small $\theta, p(\theta)$ has a Gaussian form with a maximum value at $\theta=$ 0 . A deviation of the maximum from 0 indicates tilted lipids, and therefore an ordered phase.

Such a deviation, and thus an ordered phase is observed at high concentrations of $\mathrm{S}^{-\mathrm{Gb}_{3}}$ (Fig. $5 \mathrm{~B}$ ). Also, the higher peaks of the profiles containing high percentages of $\mathrm{S}-\mathrm{Gb}_{3}$ correspond to a larger value for $\kappa_{\theta}$ and a more rigid bilayer. Thus, the increase in $\mathrm{Gb}_{3}$ concentration rigidifies the bilayer, particularly for $\mathrm{S}-\mathrm{Gb}_{3}$. To further visualise the tilt in the systems, a $2 \mathrm{D}$ tilt distribution map of the director vector density $\left(\rho\left(T_{x}, T_{y}\right)\right)$ was made. $\rho\left(T_{x}, T_{y}\right)$ was measured as the time average of the number of lipids whose director vector projection on the membrane plane is equal to $T_{x} \mathbf{i}+$ $T_{\mathrm{y}}$ j. Fig. $5 \mathrm{C}$ shows the $2 \mathrm{D}$ tilt distribution map for different systems. For $50 \% \mathrm{~S}^{-\mathrm{Gb}_{3}}$, the maximum peak is a bit shifted from the center, implying an overall non-zero average tilt for the system.

\section{Diffusion coefficient}

Lipid diffusion constants for different systems were measured by evaluating the root mean-square deviation and using the Einstein
Table 4 Diffusion constant for different systems

\begin{tabular}{|c|c|c|}
\hline System & DOPC $\mu \mathrm{m}^{2} \mathrm{~s}^{-1}$ & $\mathrm{~Gb}_{3} \mu \mathrm{m}^{2} \mathrm{~s}^{-1}$ \\
\hline $0 \mathrm{~Gb}_{3}$ & $5.5 \pm 0.8$ & - \\
\hline $12 \mathrm{U}-\mathrm{Gb}_{3}$ & $3.7 \pm 0.4$ & $3.3 \pm 0.7$ \\
\hline $12 \mathrm{~S}-\mathrm{Gb}_{3}$ & $3.2 \pm 0.5$ & $3.0 \pm 0.7$ \\
\hline $25 \mathrm{U}^{-\mathrm{Gb}_{3}}$ & $2.4 \pm 0.1$ & $2.3 \pm 0.2$ \\
\hline $25 \mathrm{~S}-\mathrm{Gb}_{3}$ & $1.2 \pm 0.2$ & $2.0 \pm 0.2$ \\
\hline $50 \mathrm{U}-\mathrm{Gb}_{3}$ & $1.8 \pm 0.1$ & $1.3 \pm 0.2$ \\
\hline $50 \mathrm{~S}-\mathrm{Gb}_{3}$ & $0.3 \pm 0.1$ & $0.4 \pm 0.1$ \\
\hline $100 \mathrm{U}-\mathrm{Gb}_{3}$ & - & $0.3 \pm 0.2$ \\
\hline $100{\mathrm{~S}-G b_{3}}$ & - & $0.4 \pm 0.3$ \\
\hline
\end{tabular}

relationship. The values are given in Table 4. High concentrations of $\mathrm{Gb}_{3}$ resulted in lower lateral diffusion coefficients of the lipid in the bilayer plane. At low concentrations, the values are close to the expected values for fluid lipid bilayers (around $8 \mu \mathrm{m}^{2}$ $\mathrm{s}^{-1}$ for $\mathrm{DOPC}^{47}$ ). Beyond $12.5 \% \mathrm{~Gb}_{3}$, the diffusion of DOPC is significantly lowered by $\mathrm{S}-\mathrm{Gb}_{3}$ and to a lesser degree by $\mathrm{U}-\mathrm{Gb}_{3}$. 


\section{Effects of $G b_{3}$ fatty acid chain length disparity}

The $\mathrm{Gb}_{3}$ lipid has a big length mismatch in its two hydrocarbon tails. The sphingosine chain has 18 carbon atoms while the acyl chain contains 22 carbon atoms. Three different states for such a chain mismatch have been suggested, which under some conditions could lead to interdigitation between the hydrocarbons of the two opposite monolayers and drive the system in a new phase state. ${ }^{48}$ In the mixed systems, the shorter $\mathrm{Gb}_{3}$ chain (sphingosine chain) is packed end to end with DOPC chains, while the $\mathrm{Gb}_{3}$ acyl chain from both the leaflets penetrate the hydrocarbon region of the opposite monolayer, more so for S$\mathrm{Gb}_{3}$ (Fig. 2). The peak in the $\mathrm{Gb}_{3}$ acyl chain density profile (Fig. 6) shows interdigitation between the acyl chains of the two opposing monolayers. The higher peak of $\mathrm{S}^{-\mathrm{Gb}_{3}}$ compared to that of $\mathrm{U}-\mathrm{Gb}_{3}$ shows that it is more favourable for $\mathrm{S}-\mathrm{Gb}_{3}$ to interdigitate into the other monolayer. Similar results are observed for lower $\mathrm{Gb}_{3}$ concentrations (data not shown).

\section{Lipid rotation}

Lipid rotation around the bilayer normal is one of the slower degrees of freedom of the lipids in a lipid bilayer. The two-time correlation function for lipid rotation is defined as
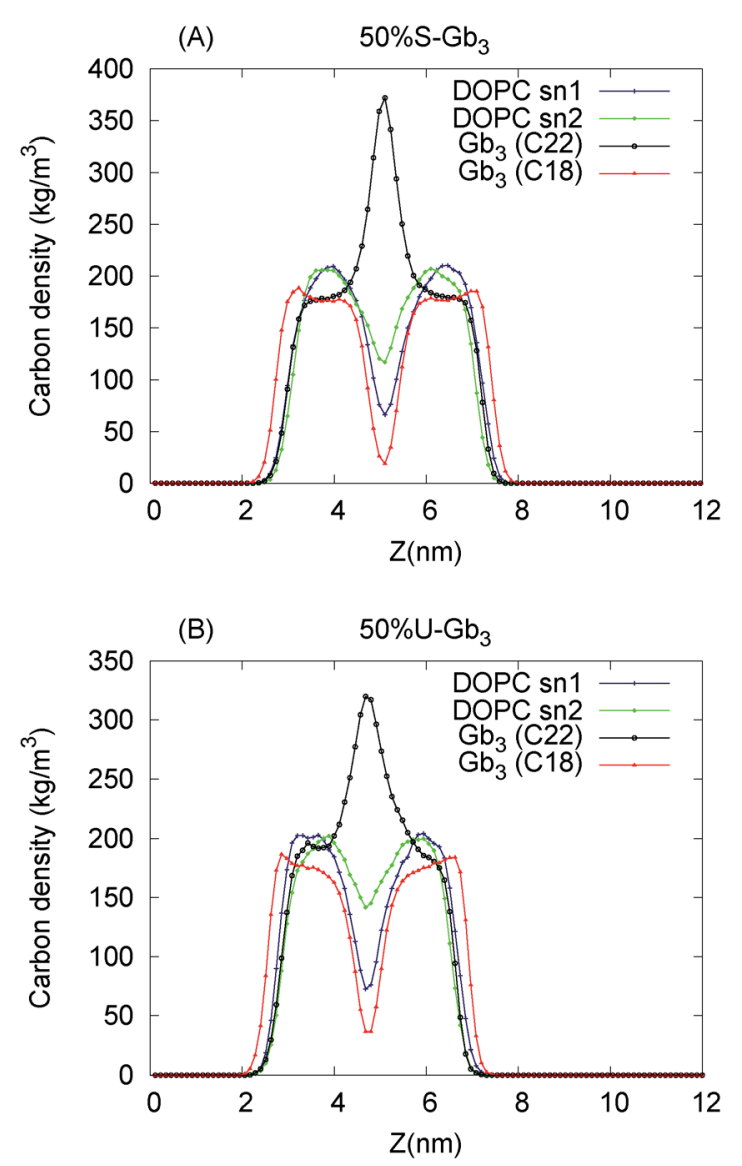

Fig. 6 Lipid fatty acid chain carbon density profile along the bilayer

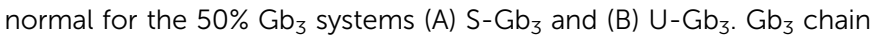
mismatch leads to interdigitation between the hydrocarbons of the two opposing monolayers. The higher peak for $\mathrm{S}-\mathrm{Gb}_{3}$ shows that it is more favourable for $\mathrm{S}-\mathrm{Gb}_{3}$ to interdigitate into the other monolayer.

$$
C_{\theta}\left(t_{0}\right)=\left\langle R_{\theta}(t) R_{\theta}\left(t+t_{0}\right)\right\rangle
$$

where $R_{\theta}(t)$ is the projection of a vector on the membrane plane, which points from the first carbon of the first chain to the first carbon of the second chain of each lipid. $\langle x\rangle$ is the ensemble average of the $x . C_{\theta}$ for $\mathrm{Gb}_{3}$ decays very slowly compared to DOPC lipids (Fig. 7), because the $\mathrm{Gb}_{3}$ lipid has a significant difference in its chain lengths that results in interdigitation. In this situation, the Gb3 lipid can rotate in two ways (1) around its principal axis: such a rotation is strongly restricted because one of the tails is interdigitated into the opposite leaflet. (2) Around its longer chain: such a rotation is also slowed down, because the axis of rotation is not along the principal axis, and the moment of inertia of the lipid increases. At high concentration of $\mathrm{Gb}_{3}$, DOPC lipids are in contact with many $\mathrm{Gb}_{3}$ lipids not only in the same leaflet, but also from the interdigitated $\mathrm{C} 22 \mathrm{~Gb}_{3}$ tails from the opposing leaflet, and this can cause DOPC to freeze. Also similar to other effects, the impact of $\mathrm{S}-\mathrm{Gb}_{3}$ is stronger than the one of $\mathrm{U}-\mathrm{Gb}_{3}$.

\section{Phase separation and mixing of $\mathrm{Gb}_{3}$ in a DOPC lipid bilayer}

The time and length scales accessible to atomistic MD simulations are in the order of $\mu \mathrm{s}$ and $10 \mathrm{~s}$ of $\mathrm{nm}$ using present soft/
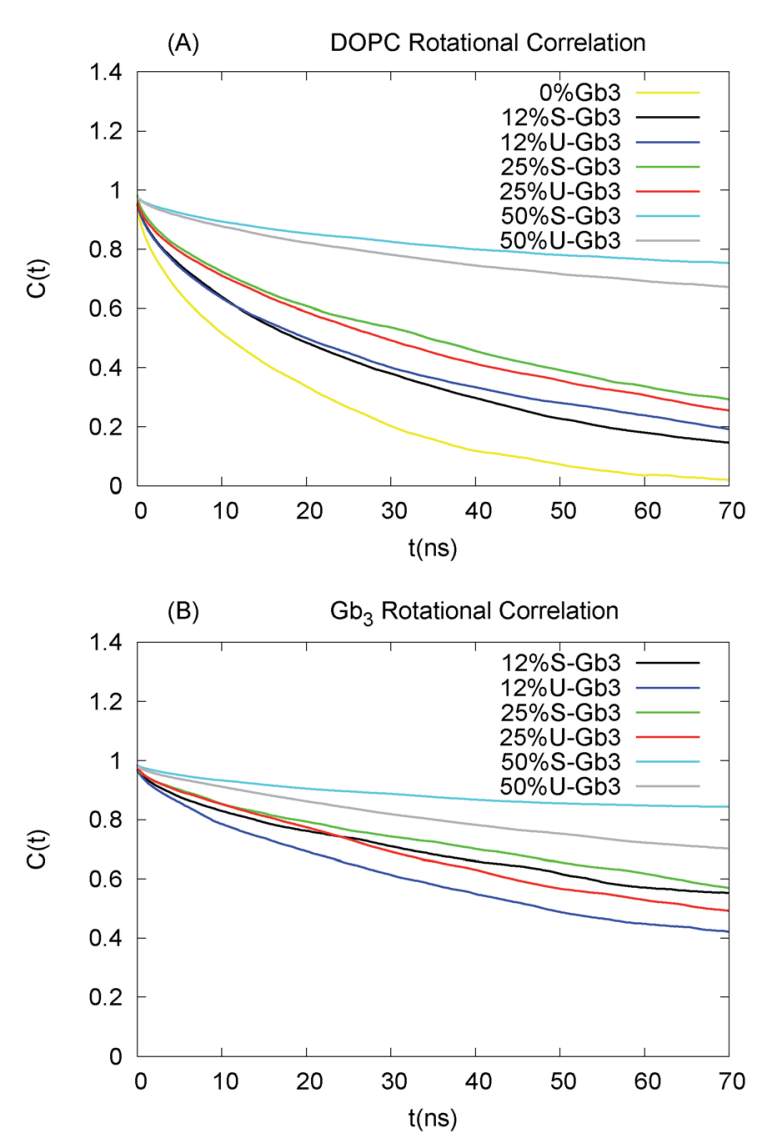

Fig. 7 Rotational correlation function: (A) $C_{\theta}$ for DOPC (B) $C_{\theta}$ for $\mathrm{Gb}_{3}$. $\mathrm{Gb}_{3}$ lipids rotate much more slowly than DOPC lipids, owing to the large mismatch in the two chain lengths of $\mathrm{Gb}_{3}$. The longer chains thus interdigitate into the opposing leaflet (see text). 
hardware. It is difficult to study the complete spontaneous phase separation of lipid mixtures without resorting to coarsegrained techniques. To deal with this, instead of waiting for the system to phase separate, a phase separated system was created and the number of mixed lipids was considered. The initial configuration contains $16 \mathrm{~Gb}_{3}$ lipids (for both $\mathrm{S}-\mathrm{Gb}_{3}$ and $\mathrm{U}-\mathrm{Gb}_{3}$ ) in a patch embedded into one monolayer of a DOPC bilayer. The simulation was then run for $400 \mathrm{~ns}$.

Two $\mathrm{U}-\mathrm{Gb}_{3}$ lipids mixed in the DOPC bilayer after $400 \mathrm{~ns}$ (Fig. 8B), while no mixing was observed for $\mathrm{S}^{-\mathrm{Gb}_{3}}$ for the same simulation time (Fig. 8A). Thus, we can hypothesize from the data that $\mathrm{U}-\mathrm{Gb}_{3}$ has a higher affinity to mix with DOPC, compared to $\mathrm{S}^{-\mathrm{Gb}_{3}}$. This effect could be because of the height

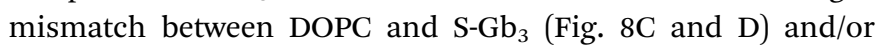
because of unfavourable contacts between the saturated acyl chain of the $\mathrm{S}-\mathrm{Gb}_{3}$ and the unsaturated DOPC chains.

The method above does not quantify phase behaviour accurately, but does provide a comparison between the mixing rates of $\mathrm{S}-\mathrm{Gb}_{3}$ and $\mathrm{U}-\mathrm{Gb}_{3}$.

\section{Discussion}

The $\mathrm{Gb}_{3}$ carbohydrate moiety, which is identical in all $\mathrm{Gb}_{3}$ types, is essential for Shiga toxin binding to a cell membrane and its subsequent internalization into the host cell. ${ }^{9}$ However, different types of $\mathrm{Gb}_{3}$ behave differently in the $\mathrm{Gb}_{3}$ involving processes. The most notable example is the inability of STxB to
(A)

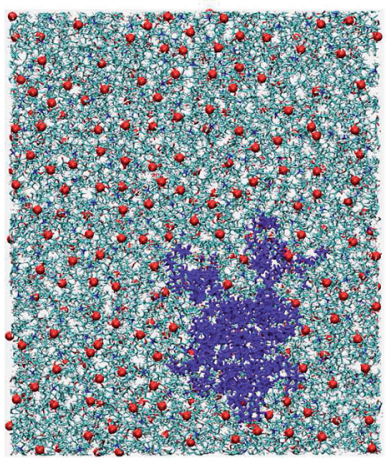

(C)

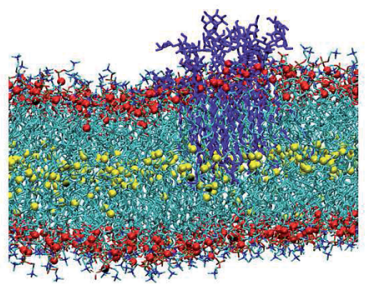

(B)

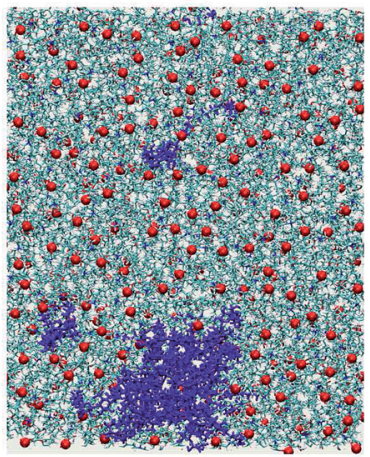

(D)

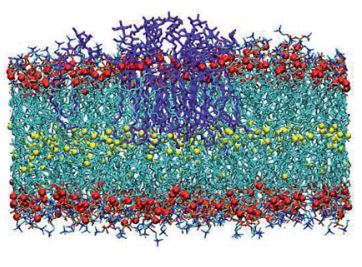

Fig. 8 Last snapshot of the phase separated systems (16 $\mathrm{Gb}_{3}$ in a DOPC lipid bilayer). After $400 \mathrm{~ns}$, (A) no S-Gb lipid is separated from the $\mathrm{S}-\mathrm{Gb}_{3}$ patch while $(\mathrm{B})$ two $U-\mathrm{G} b_{3}$ lipids diffused away from the $U$ $\mathrm{Gb}_{3}$ patch. (C) and (D) are the lateral view of (A) and (B), respectively. $A$ height mismatch between $\mathrm{S}-\mathrm{Gb}_{3}$ and DOPC can be seen while such an effect is not present for $U-G b_{3}$. The height mismatch is one of the factors leading to a lower tendency of $\mathrm{S}-\mathrm{Gb}_{3}$ to mix in the bilayer. induce tubular membrane invagination upon binding to $\mathrm{S}-\mathrm{Gb}_{3}$ on the surface of a DOPC model membrane. On the other hand, $\mathrm{STxB}$ bound to $\mathrm{U}-\mathrm{Gb}_{3}$ on the surface of a DOPC model membrane induces tubular invaginations., ${ }^{2,12}$ Thus, STxB binding to the membrane is insufficient for the formation of membrane tubular invagination and the presence of a specific $\mathrm{Gb}_{3}$ species is required.

We have used all-atom MD simulations to investigate the effects of varying the $\mathrm{Gb}_{3}$ concentration as well as the degree of unsaturation of its acyl chains on the physical properties of DOPC lipid bilayers. Our results reveal two important features of the Gb3 structure that strongly affect the structure and dynamics of the lipid bilayers when it is present at high concentrations. (1) The $\mathrm{Gb}_{3}$ chain length mismatch results in interdigitation of the longer chain into the opposite monolayer and in subsequent reduction in lipid fatty acid chain fluctuations, and ordering of all bilayer chains. The effect is stronger for $\mathrm{S}-\mathrm{Gb}_{3}$ compared to $\mathrm{U}-\mathrm{Gb}_{3}$. (2) The degree of $\mathrm{Gb}_{3}$ acyl chain saturation influences the affinity of $\mathrm{Gb}_{3}$ lipids to mix or demix in DOPC lipid bilayers.

The $\mathrm{Gb}_{3}$ concentration is low in the experiments (up to 10\%).,12 However, considering that each STxB molecule can bind up to $15 \mathrm{~Gb}_{3}$ lipids, it is reasonable to think that the $\mathrm{Gb}_{3}$ concentration is high (up to $40 \%$ ) under the protein. Combining this assumption with the fact that STXB proteins cluster on the surface of a membrane, ${ }^{2,11}$ a high concentration of $\mathrm{Gb}_{3}$ is expected in the domains enriched by STxB that modifies the local bilayer structure. This argument and the simulation results provide the following insights into several experimental observations:

(a). Binding of STxB to a bilayer containing $\mathrm{S}-\mathrm{Gb}_{3}$ and DOPC does not drive the membrane to invaginate: ${ }^{2}$ we hypothesise that invagination will not occur when STxB is bound to an ordered phase. A high energetic cost must be borne to bend such a rigid bilayer which cannot be compensated by the system. Such an ordered and rigid bilayer is observed at a high concentration of $\mathrm{S}-\mathrm{Gb}_{3}$ in our simulations, as shown in Fig. 5. A similar $l_{o}$ phase is present in a phase-separated lipid bilayer composed of DOPC, sphingomyelin, cholesterol and porcine $\mathrm{Gb}_{3}$. Binding of STXB to the $\mathrm{l}_{\mathrm{o}}$ phase of this membrane does not induce tubular invagination. ${ }^{11}$ On the other hand, $\mathrm{U}-\mathrm{Gb}_{3}$ does not form a rigid bilayer, and thus membrane invagination can occur without incurring the high bending energy penalty. Experiments also show that tubular invagination is observed upon STXB binding to a membrane containing only DOPC and $\mathrm{U}-\mathrm{Gb}_{3}$, which does not exhibit the $\mathrm{l}_{\mathrm{o}}$ phase. ${ }^{11}$

(b). For lipid bilayers containing DOPC, sphingomyelin, cholesterol and $\mathrm{Gb}_{3}-\mathrm{C} 24: 0$, which are phase separated at room temperature, no change in the area percentage of the $l_{o}$ phase was observed upon STxB binding experimentally: ${ }^{13}$ we have shown that $\mathrm{S}-\mathrm{Gb}_{3}$ tends to remain phase separated in such a DOPC bilayer. Thus, $\mathrm{SGb}_{3}$ is probably already in a phase separated state in the mixed bilayer even before STxB binds. Thus, STXB binds to the $l_{o}$ phase, and no further changes occur in the system.

(c). Increase in membrane height due to protein clustering: ${ }^{11}$ Table 3 shows that the membrane thickness increases with 
increasing $\mathrm{Gb}_{3}$ concentration. The change is particularly significant at high $\mathrm{S}-\mathrm{Gb}_{3}$ concentrations.

(d). The condensation of phospholipid-Gb3 monolayers at high Gb3 concentrations: ${ }^{16}$ increasing the $\mathrm{Gb}_{3}$ concentration induces a progressively lower area per lipid and a dramatic reduction was observed at high $\mathrm{S}-\mathrm{Gb}_{3}$ concentrations (Table 3 ). In the experiments a similar impact for $\mathrm{S}_{-} \mathrm{Gb}_{3}$ was observed. ${ }^{\mathbf{1 6}}$

Our results suggest that the STXB binding to a lipid bilayer indirectly influences the properties of the lipid bilayer by clustering and accumulating $\mathrm{Gb}_{3}$ underneath the protein aggregate. Invagination is not induced when $\mathrm{Gb}_{3}$ is saturated, because $\mathrm{S}$ $\mathrm{Gb}_{3}$ forms a rigid immobile phase resistant to bending whilst the unsaturated version does not. Our results provide several hypotheses which can resolve some of the unexplained experimental observations with regard to the phenomenon of membrane invagination induced by Shiga toxins. Further investigation is needed to validate these hypotheses.

\section{Acknowledgements}

The research leading to these results has received funding from the European Community's Seventh Framework Programme (FP7/2007-2013) under the grant agreement number TRANSPOL-264399. Some parts of the computations were carried out on the Horseshoe clusters at the SDU node for the Danish Center for Scientific Computing (DCSC). We acknowledge that the results of this research have been achieved using the PRACE-2IP project (FP7 RI-283493) resource ARCHER based on the United Kingdom at https://www.archer.ac.uk/. HK is funded by a Lundbeckfonden Young Investigator Grant. The LJ group was supported by the European Research Council advanced grant (project 340485), Agence Nationale pour la Recherche (ANR-09-BLAN-283 and ANR-11 BSV2 014 03), and Human Frontier Program organization (RGP0029/2014C101).

\section{References}

1 B. Maggio, M. L. Fanani, C. M. Rosetti and N. Wilke, Biochim. Biophys. Acta, 2006, 1758, 1992-1944.

2 W. Römer, L. Berland, V. Chambon, K. Gaus, B. Windschiegl, D. Tenza, M. Aly, V. Fraisier, J. Florent, D. Perrais, C. Lamaze, G. Raposo, C. Steinem, P. Sens, P. Bassereau and L. Johannes, Nature, 2007, 450, 670-675.

3 T. Eierhoff, B. Bastian, R. Thuenauer, J. Madl, A. Audfray, S. Aigal, S. Juillot, G. Rydell, S. Muller, S. de Bentzmann, A. Imberty, C. Fleck and W. Romer, Proc. Natl. Acad. Sci. U. S. A., 2014, 111, 12895-12900.

4 O. Kovbasnjuk, R. Mourtazina, B. Baibakov, T. Wang, C. Elowsky, M. A. Choti, A. Kane and M. Donowitz, Proc. Natl. Acad. Sci. U. S. A., 2005, 102, 19097-19092.

5 L. Johannes and D. Decadin, Gene Ther., 2005, 12, 13601368.

6 F. Sandoval, M. Terme, M. Nizard, C. Badoual, M. Bureau, L. Freyburger, O. Clement, E. Marcheteau, A. Gey, G. Fraisse, C. Bouguin, N. Merillon, E. Dransart, T. Tran, F. Quintin-Colonna, G. Autret, M. Thiebaud, F. Suleman, S. Riffault, T. Wu, O. Launay, C. Danel, J. Taieb,
J. Richardson, L. Zitvogel, W. Fridman, L. Johannes and E. Tartour, Sci. Transl. Med., 2013, 5, 172ra20.

7 H. Pere, Y. Montier, J. Bayry, N. Merillon, F. QuintinColonna, E. Dransart, C. Badoual, A. Gey, P. Ravel, F. Sandoval, C. Guerin, O. Adotevi, Y. Lone, L. Ferreira, B. Nelson, D. Hanahan, W. Fridman, L. Johannes* and E. Tartour*, Blood, 2011, 118, 4853-4862.

8 O. Adotevi, B. Vingert, L. Freyburger, P. Shrikant, Y. Lone, F. Quintin-Colonna, N. Haicheur, M. Amessou, A. Herbelin, P. Langlade-Demoyen, W. Fridman, F. Lemonnier, L. Johannes* and E. Tartour*, J. Immunol., 2007, 179, 33713379.

9 H. Ling, A. Boodhoo, B. Hazes, M. D. Cummings, G. D. Armstrong, J. L. Brunton and R. J. Read, Biochemistry, 1998, 37, 1777-1788.

10 D. G. Pina, L. Johannes and M. A. Castanho, Biochim. Biophys. Acta, 2007, 1768, 628-636.

11 B. Windschiegl, A. Orth, W. Römer, L. Berland, B. Stechmann, P. Bassereau, L. Johannes and C. Steinem, PLoS One, 2009, 4, e6238.

12 M. Safouane, L. Berland, A. Callan-Jones, B. Sorre, W. Römer, L. Johannes, G. E. S. Toombes and P. Bassereau, Traffic, 2010, 11, 1519-1529.

13 O. M. Schütte, A. Ries, A. Orth, L. J. Patalag, W. Römer, C. Steinem and D. B. Werz, Chem. Sci., 2014, 5, 3104-3114.

14 D. J. Chinnapen, W. Hsieh, Y. te Welscher, D. Saslowsky, L. Kaoutzani, E. Brandsma, L. D'Auria, H. Park, J. Wagner, K. Drake, M. Kang, T. Benjamin, M. Ullman, C. Costello, A. Kenworthy, T. Baumgart, R. Massol and W. Lencer, Dev. Cell, 2012, 23, 573-586.

15 V. Solovyeva, L. Johannes and A. C. Simonsen, Soft Matter, 2015, 11, 186-192.

16 E. B. Watkins, H. Gao, A. J. C. Dennison, N. Chopin, B. Struth, T. Arnold, J.-C. Florent and L. Johannes, Biophys. J., 2014, 107, 1146-1155.

17 H. J. C. Berendsen, D. van der Spoel and R. van Drunen, Comput. Phys. Commun., 1995, 91, 43-56.

18 E. Lindahl, B. Hess and D. van der Spoel, J. Mol. Model, 2001, 7, 306-317.

19 D. van der Spoel, E. Lindahl, B. Hess, G. Groenhof, A. E. Mark and H. J. C. Berendsen, J. Comput. Chem., 2005, 26, 1701-1718.

20 B. Hess, C. Kutzner, D. van der Spoel and E. Lindahl, J. Chem. Theory Comput., 2008, 4, 435-447.

21 P. Bjelkmar, P. Larsson, M. A. Cuendet, B. Hess and E. Lindahl, J. Chem. Theory Comput., 2010, 6, 459-466.

22 J. B. Klauda, R. M. Venable, J. A. Freites, J. W. O'Connor, D. J. Tobias, C. Mondragon-Ramirez, I. Vorobyov, A. D. MacKerell Jr and R. W. Pastor, J. Phys. Chem. B, 2010, 114, 7830-7843.

23 W. L. Jorgensen, J. Chandrasekhar, J. D. Madura, R. W. Impey and M. L. Klein, J. Chem. Phys., 1983, 79, 926935.

24 A. D. MacKerell Jr, D. Bashford, M. Bellott, J. R. L. Dunbrack, J. D. Evanseck, M. J. Field, S. Fischer, J. Gao, H. Guo, S. Ha, D. Joseph-McCarthy, L. Kuchnir, K. Kuczera, F. T. K. Lau, C. Mattos, S. Michnick, T. Ngo, D. T. Nguyen, B. Prodhom, 
W. E. R. III, B. Roux, M. Schlenkrich, J. C. Smith, R. Stote, J. Straub, M. Watanabe, J. Wiórkiewicz-Kuczera, D. Yin and M. Karplu, J. Phys. Chem. B, 1998, 102, 3586-3616.

25 H. J. C. Berendsen, J. P. M. Postma, A. DiNola and J. R. Haak, J. Phys. Chem. B, 1984, 81, 3684-3690.

26 W. G. Hoover, Phys. Rev. A, 1985, 31, 1695-1697.

27 B. Hess, H. Bekker, H. J. C. Berendsen and J. G. E. M. Fraaije, J. Comput. Chem., 1997, 18, 1463-1472.

28 M. Parrinello and A. Rahman, J. Appl. Phys., 1981, 52, 71827190.

29 S. Noséa and M. Klein, Mol. Phys., 1983, 50, 1055-1076.

30 H. J. C. Berendsen, J. P. M. Postma, A. DiNola and J. R. Haak, J. Chem. Phys., 1984, 81, 3684-3690.

31 O. Guvench, S. Greene, G. Kamath, J. Brady, R. Venable, R. Pastor and A. J. MacKerell, J. Comput. Chem., 2008, 29, 2543-2564.

32 O. Guvench, E. R. Hatcher, R. M. Venable, R. W. Pastor and A. J. MacKerell, J. Chem. Theory Comput., 2009, 5, 2353-2370.

33 E. P. Raman, O. Guvench and A. J. MacKerell, J. Phys. Chem. $B, 2010,114,12981-12994$.

34 O. Guvench, S. S. Mallajosyula, E. P. Raman, E. Hatcher, K. Vanommeslaeghe, T. J. Foster, F. W. Jamison and A. J. MacKerell, J. Chem. Theory Comput., 2011, 7, 3162-3180. 35 S. S. Mallajosyula and A. J. MacKerell, J. Phys. Chem. B, 2011, 115, 11215-11229.

36 C. M. Breneman and K. B. Wiberg, J. Comput. Chem., 1990, 11, 361-373.

37 M. J. Frisch, G. W. Trucks, H. B. Schlegel, G. E. Scuseria, M. A. Robb, J. R. Cheeseman, G. Scalmani, V. Barone, B. Mennucci, G. A. Petersson, H. Nakatsuji, M. Caricato, X. Li, H. P. Hratchian, A. F. Izmaylov, J. Bloino, G. Zheng, J. L. Sonnenberg, M. Hada, M. Ehara, K. Toyota, R. Fukuda, J. Hasegawa, M. Ishida, T. Nakajima, Y. Honda,
O. Kitao, H. Nakai, T. Vreven, J. A. Montgomery Jr, J. E. Peralta, F. Ogliaro, M. Bearpark, J. J. Heyd, E. Brothers, K. N. Kudin, V. N. Staroverov, R. Kobayashi, J. Normand, K. Raghavachari, A. Rendell, J. C. Burant, S. S. Iyengar, J. Tomasi, M. Cossi, N. Rega, J. M. Millam, M. Klene, J. E. Knox, J. B. Cross, V. Bakken, C. Adamo, J. Jaramillo, R. Gomperts, R. E. Stratmann, O. Yazyev, A. J. Austin, R. Cammi, C. Pomelli, J. W. Ochterski, R. L. Martin, K. Morokuma, V. G. Zakrzewski, G. A. Voth, P. Salvador, J. J. Dannenberg, S. Dapprich, A. D. Daniels, Ö. Farkas, J. B. Foresman, J. V. Ortiz, J. Cioslowski and D. J. Fox, Gaussian-09 Revision D.01, Gaussian Inc, Wallingford CT, 2009.

38 J. P. M. Jambeck and A. P. Lyubartsev, J. Chem. Theory Comput., 2012, 8, 2938-2948.

39 N. Kučerka, J. F. Nagle, J. N. Sachs, S. E. Feller, J. Pencer, A. Jackson and J. Katsaras, Biophys. J., 2008, 95, 2356-2367. 40 J. Pan, S. Tristram-Nagle, N. Kučerka and J. F. Nagle, Biophys.J., 2008, 94, 117-124.

41 N. Kučerka, S. Tristram-Nagle and J. F. Nagle, J. Membr. Biol., 2005, 208, 193-202.

42 G. Lukat, J. Krüger and B. Sommer, J. Chem. Inf. Model., 2013, 53, 2908-2925.

43 J. Seelg, Q. Rev. Biophys., 1977, 3, 353-418.

44 J. Douliez, A. Léonard and E. J. Dufourc, Biophys. J., 1995, 68, 1727-1739.

45 J. Aittoniemi, P. S. Niemelä, M. T. Hyvönen, M. Karttunen and I. Vattulainen, Biophys. J., 2007, 92, 1125-1137.

46 M. Hamm and M. M. Kozlov, Eur. Phys. J. E, 2000, 3, 323-335. 47 G. Lindblom and G. Orädd, Biochim. Biophys. Acta, 2009, 1788, 234-244.

48 I. W. Levin, T. E. Thompson, Y. Barenholz and C. Huang, Biochemistry, 1985, 24, 6282-6286. 